\title{
Relation between Knowledge, Attitude and Practice of Hepatitis B among Dental Undergraduates in the Kingdom of Saudi Arabia
}

\author{
Manal GY Mubaraki ${ }^{1}$, Shatha AH Alamir ${ }^{2}$, Mosaab MM Qohal ${ }^{3}$, Omar HA Alamir ${ }^{4}$, Mir FA Quadri ${ }^{5}$
}

\begin{abstract}
Aim: Dental healthcare professionals are at a considerable risk of infectious diseases such as hepatitis B (HB). The study aims to present the details on the current knowledge, attitude, and practice of dental students towards HB in the Kingdom of Saudi Arabia.

Materials and methods: A cross-sectional study was designed targeting fifth academic year and 6 th academic year dental students as well as dental interns. Knowledge, attitude, and practice of HB were checked using a self-reported questionnaire. Wherein, 11 questions were about knowledge, 6 about attitude, and the final 6 were on practice. Chi-square analysis was followed by Spearman's correlation to report on the relation between knowledge, attitude, and practice. SPSS version 24 was used for analyzing the data.

Results: The response rate was $87 \%$ of which, $41 \%$ were females, and $59 \%$ were males. It was seen that $61.3 \%$ of the respondents had good knowledge, $55 \%$ indicated a positive attitude, and $77 \%$ of them demonstrated safe practices. We also observed that the students or interns with good grade point average (GPA) had the strongest correlation $(r=0.70 ; p<0.001)$ with their knowledge on HB. Knowledge was also significantly correlated with the attitude $(r=0.373, p<0.001$ and safe practices $(r=0.11, p=0.004)$ of HB among the students and the interns. Conclusion: Findings from the current research conclude that having good knowledge on HB accounts for a positive attitude and safe practices among undergraduate dental students.

Clinical significance: Potential oral health practitioners at dental schools should have a thorough knowledge of infectious diseases such as HB so that they implement safe practices from an early stage. The medical and dental curriculum should be reformed to include specific learning outcomes in every clinical course on stringent and effective ways to implement infection control practices.

Keywords: Attitude, Dentist, Hepatitis B, Knowledge, Practice.

The Journal of Contemporary Dental Practice (2019): 10.5005/jp-journals-10024-2716
\end{abstract}

\section{BACKGROUND}

Hepatitis $B$ is a disease or condition affecting the liver with the calculated global mortality rate of 6,00,000 per year. ${ }^{1}$ People suffering from this deadly disease have inflamed liver leading to hampered overall body functions and eventually causing death. The symptoms are not known when newly infected, however, there can be acute illness with symptoms such as yellowing of skin and eyes, nausea, vomiting, and abdominal pain that could last for several weeks. ${ }^{2}$ Recent publications reveal that over 2 billion people are suffering from this dreadful disease and nearly 350 million carriers of the virus. ${ }^{3}$ The estimated world prevalence of $\mathrm{HB}$ is ranging from $0.1 \%$ to $20 \%$, between the lowest and the highest endemic areas. ${ }^{4}$ With the growing number of new cases, $\mathrm{HB}$ is now considered as a "disease of priority" by an updated report. ${ }^{5}$ Furthermore, countries that are part of the Asian continent, especially the ones in the middle eastern regions have been projected with a high prevalence ranging from 10 million to 15 million. ${ }^{6}$

Though the overall prevalence of $\mathrm{HB}$ is considerably low among males and females residing in Saudi Arabia, it is to be noted that this percentage is more among 18-21-year-olds and also comparatively rises among the people residing in rural regions of the country. ${ }^{7,8} \mathrm{It}$ is of utmost importance that the populations, in general, should have a basic knowledge about $\mathrm{HB}$, especially the ones who are at greater risk. Reports have previously have shown that the knowledge of $\mathrm{HB}$ among people residing in different regions of the world is fairly low. ${ }^{9-13}$ Similar to this, a study conducted in Saudi Arabia has also
${ }^{1-4}$ Deparment of General Dentistry, Ministry of Health, Kingdom of Saudi Arabia

${ }^{5}$ Department of Preventive Dental Sciences, College of Dentistry, Jazan University, Kingdom of Saudi Arabia

Corresponding Author: Mir FA Quadri, Department of Preventive Dental Sciences, College of Dentistry, Jazan University, Kingdom of Saudi Arabia, Phone: +966 598959409 e-mail: dr.faeq.quadri@gmail.com

How to cite this article: Mubaraki MGY, Alamir SAH, Qohal MMM, et al. Relation between Knowledge, Attitude and Practice of Hepatitis B among Dental Undergraduates in the Kingdom of Saudi Arabia. J Contemp Dent Pract 2019;20(12):1447-1455.

Source of support: Research Unit, College of Dentistry, Jazan University Conflict of interest: None

revealed that a very smaller number of participants knew about HB and its prophylactic measures. ${ }^{8}$ Some findings from the northern and eastern regions of Saudi Arabia have also been reported, but there are no such reports from the southern province of Saudi Arabia, which is still developing and trying to align itself with the urban sections of this vast nation.

Similarly, health care practitioners are at a higher probability of contracting $\mathrm{HB}$ infection as they are in close proximity to infectious materials or sharp infected needles. This high risk of occupational exposure may affect the safety of the practitioners and questions the quality of care. Jazan University and King Khaled University are the largest free-oral-health service providers in the southern region 
through their undergraduate and graduate students. Authors here propose that dental health care professionals (DHCP) learning and practicing in this developing region are at a considerably higher risk of infectious diseases such as $\mathrm{HB}$; and it is extremely important that these DHCP should have sufficient knowledge, attitude and practice towards $\mathrm{HB}$ in order to prevent potential cross infections. Thus, the objective of this study is to present the details on the current knowledge, attitude, and practice of dental undergraduate students towards HB.

\section{Materials and Methods}

\section{Ethical Clearance}

The current study was part of an internship completion project, hence approval from the research committee (dated: 08-08-2017) at the College of Dentistry, Jazan University was primarily sorted. Informed and signed consent from the study participants was also taken subsequently before administering the questionnaire.

\section{Study Design and Subjects}

A cross-sectional study was designed and conducted targeting all the 5th year and 6th year dental students as well as the dental interns of Jazan University and King Khaled University in Saudi Arabia. Targeted sample was $535(n)$, and participation, in this study, was completely voluntary with no incentive given to any of the respondents.

\section{Study Instrument and its Administration}

A modified version of a previously designed questionnaire was used in order to measure the knowledge, attitude, and practice of the target population. ${ }^{14}$ This modified version had 23 questions wherein, 11 questions were about knowledge, 6 about attitude, and the final 6 on practice. Translation into Arabic was not performed as the medium of education at these universities is in English. But, the understandability of the questionnaire was checked in a pilot population of 20 students and 10 interns $(r=0.86) .^{15}$

Students and interns were approached during their routine clinical sessions on separate days, as they were gender-segregated.
The data from the male participants was collected on the 28th of January 2018 and for the female participants on the 29th of January 2018. The responses were taken electronically using an iPad. This type of data collection method was adopted to increase the response rate, as most of the previous studies had a low response rate recorded if the instruments were emailed. In addition to this, data collection procedures in a similar situation or environment (clinical sessions) decreased the chances of other simultaneous influences to their responses. Good knowledge, attitude, and practice of the dental students and interns were considered if the aggregate score obtained was equal to or more than the median score.

\section{Statistical Analyses}

SPSS version 24 was used for analyzing the data. $p$ value equal to or less than 0.05 was considered as significant. At first, descriptive analysis was performed, followed by normality tests. As the data were normally distributed, a Chi-square test was performed to see the association between independent and dependent variables (knowledge, attitude, and practice). Later spearman's correlation was checked to report on the relation between knowledge, attitude, and practice of HB among dental students and interns.

\section{Results}

The response rate from the originally targeted population of 535 , was $87 \%$ ( $n=466$ ), indicating that a fair number of dental students and interns agreed to respond to the questionnaire. Sociodemographic characteristics showed that $41 \%$ of the study population were females, and $59 \%$ were males. The age range was from 18 years to 26 years, with a mean age of $24 \pm 0.1$ years, and only $38 \%$ of the respondents were vaccinated (Table 1 ).

On identifying the knowledge, attitude, and practice of the respondents, it was seen that $61.3 \%$ of the respondents had good knowledge of HB (more than median), 55\% indicated a positive attitude, and $77 \%$ of them demonstrated safe practices (Table 2 ). As high as $81 \%$ of the respondents were aware that carriers of the virus may also transmit the infection. $86.5 \%$ of the dental students

Table 1: Frequency distribution of hepatitis B knowledge, attitude and practice with regards to the assessed variables $(n=466)$

\begin{tabular}{|c|c|c|c|c|c|c|}
\hline \multirow[b]{2}{*}{ Variables } & \multicolumn{2}{|c|}{ Knowledge } & \multicolumn{2}{|c|}{ Attitude } & \multicolumn{2}{|c|}{ Practice } \\
\hline & Good (61.3\%) & Poor (38.7\%) & Positive (55\%) & Negative (45\%) & Safe (77\%) & Unsafe (33\%) \\
\hline \multicolumn{7}{|l|}{ Gender } \\
\hline Male 275 (59\%) & $132(48)$ & $143(52)$ & $136(49.2)$ & $140(50.8)$ & $177(64.5)$ & $98(35.5)$ \\
\hline Female 191 (41\%) & $97(51)$ & $93(49)$ & $99(51.8)$ & $92(48.2)$ & $144(75.5)$ & $47(24.5)$ \\
\hline \multicolumn{7}{|l|}{ Level of education } \\
\hline 5th year $150(32.2 \%)$ & $71(47.5)$ & $79(52.5)$ & $76(50.8)$ & $74(49.2)$ & $100(66.7)$ & $50(33.3)$ \\
\hline 6th year $160(34.3 \%)$ & $69(43.2)$ & $91(56.8)$ & $76(47.6)$ & $84(52.4)$ & $120(75.2)$ & $40(24.8)$ \\
\hline Intern 156 (34.5\%) & $87(55.7)$ & $69(44.3)$ & $88(56.5)$ & $68(43.5)$ & $129(83.0)$ & $26(17.0)$ \\
\hline \multicolumn{7}{|l|}{ Age group } \\
\hline $21-25$ years $142(30.5 \%)$ & $70(49.5)$ & $72(50.5)$ & $73(51.4)$ & 69 (48.6) & $65(46.0)$ & $77(54.0)$ \\
\hline $26-30$ years $324(69.5 \%)$ & $164(50.5)$ & $160(49.5)$ & $172(53.0)$ & $152(47.0)$ & $200(61.8)$ & $124(38.2)$ \\
\hline \multicolumn{7}{|l|}{ Periodic screening } \\
\hline Yes 233 (50\%) & $177(76.0)$ & $56(24)$ & $156(67.0)$ & $77(33.0)$ & $161(69.1)$ & $72(30.9)$ \\
\hline No 233 (50\%) & $57(24.4)$ & $156(66.6)$ & $77(33.0)$ & $156(67.0)$ & $72(30.9)$ & $161(69.1)$ \\
\hline \multicolumn{7}{|l|}{ Vaccinated } \\
\hline Yes 177 (38\%) & $117(65.9)$ & $60(34.1)$ & $110(62.3)$ & 67 (37.7) & $113(63.9)$ & $64(36.1)$ \\
\hline No 289 (62\%) & $117(40.7)$ & $172(59.3)$ & $133(46.2)$ & $155(53.8)$ & $142(49.3)$ & $147(50.7)$ \\
\hline
\end{tabular}

$n(\%)=$ frequency (percentage) 
Table 2: Hepatitis B knowledge scores among undergraduate dental students

\begin{tabular}{|c|c|c|c|}
\hline Knowledge items & & $n$ & $\%$ \\
\hline \multirow[t]{3}{*}{ Do you recollect the symptoms of HBV } & Do not know & 37 & 8.0 \\
\hline & No & 77 & 16.5 \\
\hline & Yes & 351 & 75.5 \\
\hline \multirow{3}{*}{$\begin{array}{l}\text { Do you know if HBV carriers can trans- } \\
\text { mit infection }\end{array}$} & Do not know & 37 & 8.0 \\
\hline & No & 51 & 11.0 \\
\hline & Yes & 377 & 81.0 \\
\hline \multirow{3}{*}{$\begin{array}{l}\text { Dentists at higher risk of HBV than } \\
\text { general population }\end{array}$} & Do not know & 28 & 6.0 \\
\hline & No & 417 & 89.5 \\
\hline & Yes & 21 & 4.5 \\
\hline \multirow[t]{3}{*}{ An open wound/cut can transmit HBV } & Do not know & 28 & 6.0 \\
\hline & No & 63 & 13.5 \\
\hline & Yes & 375 & 80.5 \\
\hline \multirow{3}{*}{$\begin{array}{l}\text { Do you recollect the intervals for } \\
\text { immunization of HBV }\end{array}$} & Do not know & 9 & 2.0 \\
\hline & No & 70 & 1.5 \\
\hline & Yes & 450 & 96.5 \\
\hline \multirow{3}{*}{$\begin{array}{l}\text { An unsterilized syringe, needle or } \\
\text { surgical instruments can transmit HBV }\end{array}$} & Do not know & 19 & 4.0 \\
\hline & No & 163 & 3.5 \\
\hline & Yes & 431 & 92.5 \\
\hline \multirow[t]{3}{*}{ HBV can be transmitted by unsafe sex } & Do not know & 256 & 5.5 \\
\hline & No & 70 & 15.0 \\
\hline & Yes & 370 & 79.5 \\
\hline \multirow[t]{3}{*}{ Vaccine can prevent HBV infection } & Do not know & 14 & 3.0 \\
\hline & No & 49 & 10.5 \\
\hline & Yes & 403 & 86.5 \\
\hline \multirow{3}{*}{$\begin{array}{l}\text { A laboratory test is required in case of } \\
\text { mishap }\end{array}$} & Do not know & 21 & 4.5 \\
\hline & No & 2 & 0.5 \\
\hline & Yes & 443 & 95.0 \\
\hline \multirow[t]{3}{*}{ HBV has post exposure prophylaxis } & Do not know & 126 & 27.0 \\
\hline & No & 42 & 9.0 \\
\hline & Yes & 298 & 64.0 \\
\hline \multirow[t]{3}{*}{ HBV can be cured/treated } & Do not know & 86 & 18.5 \\
\hline & No & 123 & 26.5 \\
\hline & Yes & 256 & 55.0 \\
\hline
\end{tabular}

$n(\%)=$ frequency (percentage)

and interns agreed that vaccination is an essential step towards the prevention of $\mathrm{HB}$. On the contrary, it is to be noted that only half (50\%) of the dental students and interns have undergone a periodic screening for HB (Table 1). With regards to the attitude, it was observed that around $80 \%$ and $90 \%$ of the undergraduate dental students $\mathrm{HB}$ affirmed that vaccine and following infection control guidelines, to be safe and effective ways towards preventing the potential transmission of infection, respectively (Table 3). About $50 \%$ of them did not feel comfortable treating patients with $\mathrm{HB}$ (Table 3). In terms of safe practices, it was seen that $66 \%$ were screened for $\mathrm{HB}$ at least once in their lifetime. Also, around $92 \%$ said that they would report if they ever had a needle injury; whereas, only $10 \%$ of the undergraduate students have reported that they had a needle stick injury at least once in their term (Table 4).

A positive correlation was seen among some combinations of variables. We observed that the students or interns with a good GPA had the strongest correlation $(r=0.70 ; p<0.001)$ with their knowledge on $\mathrm{HB}$. It was also seen that knowledge on HB was significantly correlated with the attitude $(r=0.373, p<0.001)$ and
Table 3: Hepatitis B attitude scores among undergraduate dental students

\begin{tabular}{llrr}
\hline Questions & & \multicolumn{2}{c}{$n$} \\
\hline I have no concern of being infected & Agree & 93 & 20.0 \\
with HBV & Disagree & 280 & 60.0 \\
& Do not know & 93 & 20.0 \\
HBV vaccine is safe and effective & Agree & 375 & 80.5 \\
& Disagree & 42 & 9.0 \\
& Do not know & 49 & 10.5 \\
Change of the gloves during blood & Agree & 5 & 10.0 \\
collection is a waste of time & Disagree & 380 & 81.5 \\
& Do not know & 40 & 8.5 \\
All patients should be tested for HBV & Agree & 235 & 50.5 \\
before they receive health care & Disagree & 128 & 27.5 \\
& Do not know & 102 & 22.0 \\
I do not feel comfortable to take care & Agree & 233 & 50.0 \\
of people with HBV & Disagree & 233 & 50.0 \\
& Do not know & 0 & 0.0 \\
Following infection control guidelines & Agree & 419 & 90.0 \\
will protect me from being infected by & Disagree & 0 & 0.0 \\
HBV at work & Do not know & 47 & 10.0 \\
\hline
\end{tabular}

$n(\%)=$ frequency (percentage)

safe practice $(r=0.11, p=0.004)$ of $\mathrm{HB}$ among the students and the interns (Table 5).

\section{Discussion}

This study was conducted to check the level of knowledge, attitude, and practice on HB that the dental students and interns of the southern region of Saudi Arabia possessed. We found out that the level of knowledge was good for almost all the respondents, and more than half had a positive attitude and good practices of preventing $\mathrm{HB}$ infection, respectively. Findings by Ahmad et al., from a university in Malaysia were in accordance with the current study. ${ }^{16}$ It was also seen that another recent study conducted by Alhowaish in 2017 among the DHCP of the Northern Border University in Saudi Arabia showed similar findings. ${ }^{17}$ However, we would like to reiterate that periodic screening of $\mathrm{HB}$ among the $\mathrm{DHCP}$ is a very important criterion towards prevention and early detection, and only half of the dental students and interns have reported having undergone this type of screening. This is in contrast to other universities in developed countries where it is mandatory that the students, interns, and other DCHP undergo routine screening for $\mathrm{HB}$ and other infectious diseases. ${ }^{16,18}$

In this study, there were more male respondents in comparison to the female respondents, and this was due to the fact that the strength of male students in the 5 th year and 6 th year clinical sessions at the time of the study was a little more than the female students. Unsurprisingly, female students had a little more aggregate of knowledge, attitude, and practice scores than the male students, and this was directly correlated with their GPAs. This finding was in accordance with a study performed among a group of medical students in Pakistan ${ }^{19}$ by Khan et al. and also by Cheung et al. among Southeast Asians residing in Canada ${ }^{20}$ but a recent study performed by Ahmad et al. in Malaysia showed contrasting results. ${ }^{16}$

We also saw that the level of knowledge, attitude, and practice was on a lower side among the 5th year students, then increased among the 6th year students, and a high level of aggregate was seen 
Table 4: Hepatitis B practice scores among undergraduate dental students

\begin{tabular}{lllr}
\hline Questions & & $n$ & \multicolumn{1}{l}{$\%$} \\
\hline Have you ever screened for & No & 156 & 33.5 \\
& Yes & 310 & 66.5 \\
I always change gloves for & No & 21 & 4.5 \\
each patient during blood & Yes & 445 & 95.5 \\
taking & & 419 & 90.0 \\
Have you ever had a needle & No & 46.6 & 10.0 \\
prick injury & Yes & 37 & 8.0 \\
I always report for needle & No & 429 & 92.0 \\
prick injury & Yes & 212 & 45.5 \\
Have you been vaccinated & No & 301 & 64.5 \\
against HBV? & Yes & 177 & 38.5 \\
How many doses of HBV & No dose received & 123 & 26.5 \\
vaccine did you receive & One dose & 130 & 28.0 \\
& Three doses & 126 & 27.0 \\
\hline
\end{tabular}

$n(\%)=$ frequency (percentage)

Table 5: Correlation between knowledge, attitude and practice among the undergraduate dental students

\begin{tabular}{lllll}
\hline & GPA & Knowledge & Attitude & Practice \\
\hline GPA & 1 & $r=0.70 ;$ & $r=0.85 ;$ & $r=0.81 ;$ \\
Knowledge & & $p<0.001$ & $p<0.05$ & $p<0.05$ \\
& 1 & $r=0.373 ;$ & $r=0.11 ;$ \\
Attitude & & & $p<0.001$ & $p=0.004$ \\
& & & & $r=0.71 ;$ \\
Practice & & & & $p=0.05$ \\
\hline
\end{tabular}

$r$, coefficient of correlation

among the interns. This finding corroborates with other studies that intend to analyze the change in the level of knowledge, attitude, and practice with the level of education. ${ }^{16,18,21,22}$ The correlation between knowledge, attitude and practice among the participants provides an affirmation that having a good knowledge about a disease could surely improve the practices of prevention; and hence it is important that every clinical course taught ay undergraduate level should extensively provide updated information on disease transmission and prevention measures in order to help in combating these infectious diseases among the most vulnerable set of populations such as the dental and other medical practitioners. This type of positive association between knowledge, attitude, and practice was also demonstrated by ul Haq et al., through their study conducted among a subset of Pakistanis. ${ }^{23}$

Although the current study exhibits fairly important findings among a population of dental graduates, which have never been interviewed before on the topic of $\mathrm{HB}$, the authors here would like to emphasize that these findings cannot be generalized even to the population of similar age in the region or the nation as a whole. The participants in this study are from a science background and have shown higher knowledge, attitude, and practices in terms of $\mathrm{HB}$, whereas if a similar study is performed among the general population, then it may reveal significantly contrasting results. In conclusion, we state that the high level of knowledge, attitude, and practices among the undergraduate dentists of the southern region of Saudi Arabia should be considered as an asset towards a greater goal of attaining a hundred percent compliance of infection efficient control practices. This could be achieved if schools graduating medical and dental practitioners reform their curriculum to include specific learning outcomes in every clinical course on stringent and effective ways to implement infection control practices. Finally, periodic screening of dental undergraduates should be a mandatory procedure inside the dental schools.

\section{Public Health Significance}

The government of Saudi Arabia has formulated a road map to 2030, and improving health by eliminating communicable diseases has been prioritized. Prevention of such diseases should be worked upon horizontally and vertically, and this type of approach will only be effective if the future oral health care providers are well aware and trained to combat communicable diseases. Findings from the current study suggest an important link between knowledge, attitude, and practice. Thus, effective public health strategies need to be implemented that enhance the knowledge on $\mathrm{HB}$ among the community in general and health care providers in specific.

\section{Author's Contributions}

Manal GY Mubaraki initiated the idea of the current study. Mir FA Quadri designed and implemented the study. Shatha A Alamir, Mosaab MM Qohal, and Omar HA Alamir did the data collection, follow-up, and the data entry for the current study. Finally, Mir FA Quadri completed the analysis, followed by the drafting of the manuscript.

\section{ACKnOWLedgments}

The authors would like to acknowledge the research committees at Jazan University and King Khaled University for granting permission to approach the undergraduate students of their respective institutions in order to collect the data. We would also like to thank Mr Abdullah Abdulrahman Saqqar Alnazi for his continuous support throughout the current study.

\section{References}

1. Momin B, Richardson L. An analysis of content in comprehensive cancer control plans that address chronic hepatitis $B$ and $C$ virus infections as major risk factors for liver cancer. J Community Health 2012;37(4):912-916. DOI: 10.1007/s10900-011-9507-y.

2. WHO. Oral health surveys: basic methods. 5th ed., Annex 8; 2018; WHO - Oral health questionnaire for children.

3. Schillie S, Murphy TV, Sawyer M, et al. CDC guidance for evaluating health-care personnel for hepatitis B virus protection and for administering postexposure management. MMWR Recomm Rep 2013;62(RR-10):1-19.

4. Hatzakis A, Van Damme P, Alcorn K, et al. The state of hepatitis B and $C$ in the Mediterranean and Balkan countries: report from a summit conference. J Viral Hepat 2013;20(Suppl 2):1-20. DOI: 10.1111/ jvh.12120.

5. Lok AS, McMahon BJ. Chronic hepatitis B: update 2009. Hepatology 2009;50(3):661-662. DOI: 10.1002/hep.23190.

6. André F. Hepatitis B epidemiology in Asia, the Middle East and Africa. Vaccine 2000;18(Suppl 1):S20-S22. DOI: 10.1016/S0264410X(99)00456-9.

7. Abdul Salam A, Elsegaey I, Khraif R, et al. Population distribution and household conditions in Saudi Arabia: reflections from the 2010 Census. Springerplus 2014;3:530. DOI: 10.1186/2193-1801-3-530.

8. Al-Ajlan A. Prevalence of hepatitis B and C among students of health colleges in Saudi Arabia. East Mediterr Health J 2011;17(10):759-762. DOI: 10.26719/2011.17.10.759. 
9. Adebamowo CA, Odukogbe AA, Ajuwon AJ. Knowledge, attitude, and practices related to hepatitis $B$ virus infection among Nigerian obstetricians and midwives. J Obstet Gynaecol 1998;18(6):528-532. DOI: 10.1080/01443619866255.

10. Mesfin YM, Kibret KT. Assessment of knowledge and practice towards hepatitis B among medical and health science students in Haramaya University, Ethiopia. PLoS One 2013;8(11):e79642. DOI: 10.1371/journal. pone.0079642.

11. Kassebaum N, Arora M, Barber R, et al. Global, regional, and national disability-adjusted life-years (DALYs) for 315 diseases and injuries and healthy life expectancy (HALE), 1990-2015: a systematic analysis for the Global Burden of Disease Study 2015. Lancet 2016;388(10053):1603-1658. DOI: 10.1016/S0140-6736(16)31460-X.

12. Khosravanifard B, Rakhshan V, Ghasemi M, et al. Tehran dentists' selfreported knowledge and attitudes towards HIV/AIDS and observed willingness to treat simulated HIV-positive patients. East Mediterr Health J 2012;18(9):928-934. DOI: 10.26719/2012.18.9.928.

13. Frambo AA, Atashili J, Fon PN, et al. Prevalence of HBsAg and knowledge about hepatitis B in pregnancy in the Buea Health District, Cameroon: a cross-sectional study. BMC Res Notes 2014;7:394. DOI: 10.1186/1756-0500-7-394.

14. Al-Hazmi AH. Knowledge, attitudes and practice of dentists concerning the occupational risks of hepatitis B virus in Al Jouf Province, Saudi Arabia. Niger J Clin Pract 2015;18(2):276-281. DOI: 10.4103/1119-3077.151067.

15. Bland JA, Altman DG. Cronbach's alpha. BMJ 1997;314(7080):572. DOI: 10.1136/bmj.314.7080.572.

16. Ahmad A, Munn Sann L, Abdul Rahman H. Factors associated with knowledge, attitude and practice related to hepatitis $B$ and $C$ among international students of Universiti Putra Malaysia. BMC Public Health 2016;16:611. DOI: 10.1186/s12889-016-3188-5.
17. Alhowaish MA, Alhowaish JA, Alanazi YH, et al. Knowledge, attitudes and practices toward prevention of hepatitis $B$ virus infection among medical students at Northern Border University, Arar, Kingdom of Saudi Arabia. Electron Physician 2017;9(9):5388-5394. DOI: $10.19082 / 5388$.

18. Quadri FA, Hendriyani $H$, Pramono A, et al. Knowledge, attitudes and practices of sweet food and beverage consumption and its association with dental caries among schoolchildren in Jazan, Saudi Arabia. East Mediterr Health J 2015;21(6):403-411. DOI: 10.26719/2015.21.6.403.

19. Khan N, Ahmed SM, Khalid MM, et al. Effect of gender and age on the knowledge, attitude and practice regarding hepatitis $B$ and $C$ and vaccination status of hepatitis $B$ among medical students of Karachi, Pakistan. J Pak Med Assoc 2010;60(6): 450-455.

20. Cheung J, Lee TK, Teh CZ, et al. Cross-sectional study of hepatitis $B$ awareness among Chinese and Southeast Asian Canadians in the Vancouver-Richmond community. Can J Gastroenterol 2005;19(4):245-249. DOI: 10.1155/2005/583406.

21. Lee $\mathrm{HO}$, Lee OJ, Kim S, et al. Differences in knowledge of hepatitis $B$ among korean immigrants in two cities in the rocky mountain region. Asian Nurs Res (Korean Soc Nurs Sci) 2007;1(3):165-175. DOI: 10.1016/ S1976-1317(08)60019-5.

22. Quadri MFA, Shubayr MA, Hattan $A H$, et al. Oral hygiene practices among Saudi Arabian children and its relation to their dental caries status. Int J Dent 2018;2018:3234970. DOI: 10.1155/2018/ 3234970.

23. ul Haq N, Hassali MA, Shafie AA, et al. A cross sectional assessment of knowledge, attitude and practice towards hepatitis $B$ among healthy population of Quetta, Pakistan. BMC Public Health 2012;12:692. DOI: 10.1186/1471-2458-12-692. 


\section{Questionnaire Used}

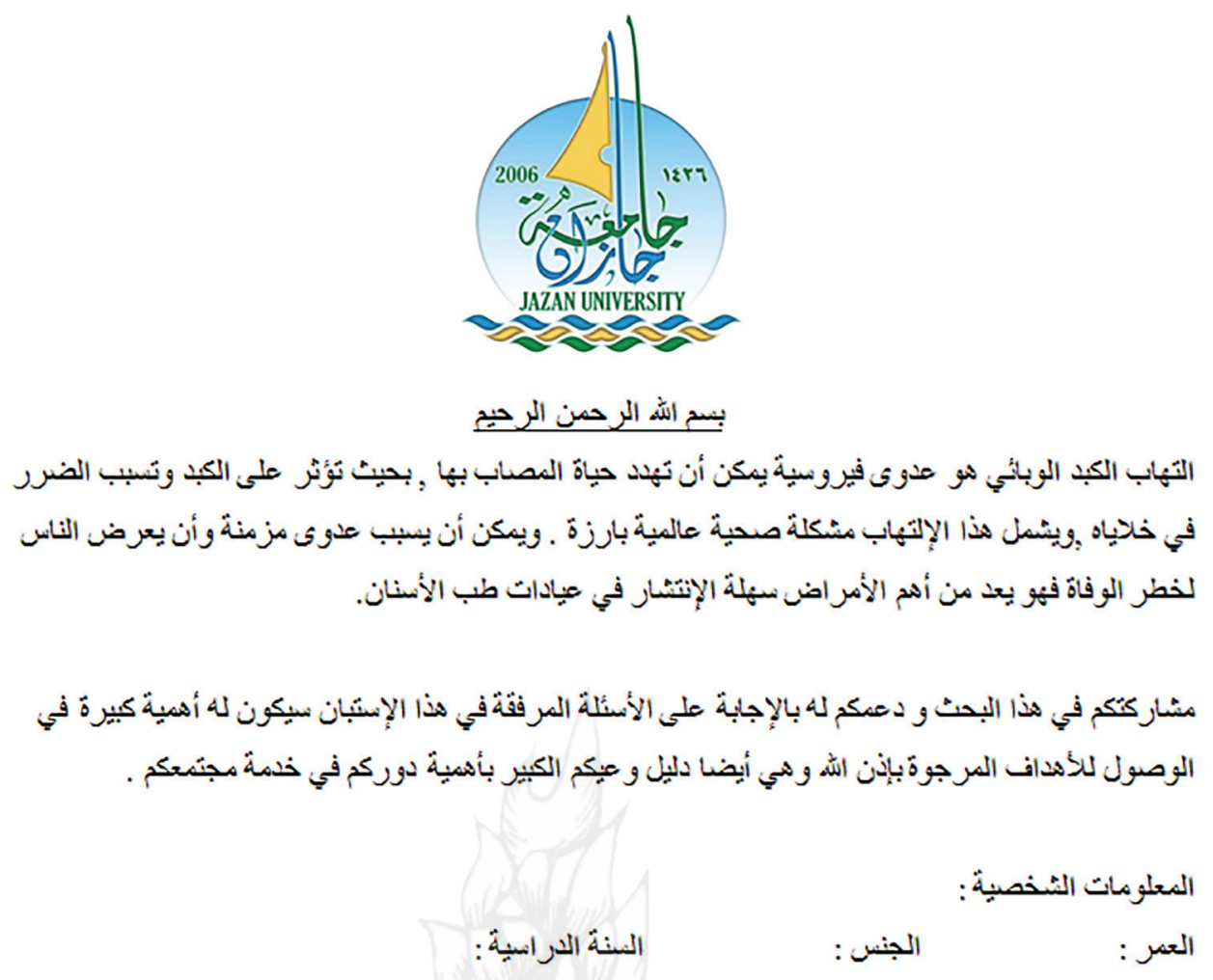

Hepatitis is a viral infection that can threaten the patient's life, so that affects the liver and cause damage in cells, and this includes inflammation prominent global health problem. It can cause chronic infection, and to expose people to the risk of death, it is one of the most important diseases, easily spread in dental clinics.

Your participation in this research and support him to answer the questions attached to this questioner would have great importance in reaching the desired targets, God willing, and is also evidence of the great consciousness of the importance of your role in your community service.

Personal information

Age

Gender

Academic year

(Knowledge)

What are the sources of your information about hepatitis (A-B-C-D)?

(A) Periphery (such as friends and neighbors)

(B) School or university

(C) Media

Do you agree that dental students have sufficient information on hepatitis?
(A) Yes
(B) No
(C) I do not know

Have you heard about hepatitis before?
(A) Yes
(B) No
(C) I do not know

Hepatitis is an infectious disease that spreads through virus?
(A) Yes
(B) $\mathrm{No}$
(C) I do not know

The appearance of the symptoms of the disease is immediately after infection?
(A) Yes
(B) No
(C) I do not know 
Prominent clinical feature of hepatitis B:
(A) Fever
(B) Jaundice
(C) Nausea

HBV infection transmitted by:

(A) Parenteral-sexual and perinatal only

(B) Contaminated water/food prepared by person

(C) Both

What is ideal age of vaccination:

(A) Infancy

(B) Adulthood

(C) I do not know

There is a vaccine for hepatitis $B$ ?
(A) Yes
(B) No
(C) I do not know

Are you vaccinated against hepatitis $B$ ?
(A) Yes
(B) No
(C) I do not know

The immunization doses are taken at intervals of:
(A) 0, 1, 6 months
(B) 0, 1, 3, 6 months
(C) I do not know

Dose a positive $(\mathrm{HbsAg})$ indicate that person is diseased and infective?
(A) Yes
(B) No
(C) I do not know

Dentists are at higher risk of HBV infection than the general population?
(A) Yes
(B) No
(C) I do not know

Is hepatitis B transmitted through tattoo or acupuncture needles?
(A) Yes
(B) No
(C) I do not know

In health care professionals, can hepatitis B be transmitted through blood splashing into mucous membranes of the eye or mouth?

(A) Yes

(B) No

(C) I do not know

Should individuals with hepatitis B or C infection receive dental treatment in hospital?
(A) Yes
(B) No
(C) I do not know

Are you aware of the first aid treatment in case of accidental exposure to hepatitis B?
(A) Yes
(B) No
(C) I do not know

Do you know the precautionary measures to be taken against hepatitis B in your routine practice?
(A) Yes
(B) No
(C) I do not know

Would you have joined this profession after knowing the potential risk of exposure to hepatitis B?
(A) Yes
(B) $\mathrm{No}$
(C) I do not know

After patient treatment procedure, materials which have contact with body fluids and blood must be chucked to medical waste?
(A) Yes
(B) No
(C) I do not know 
Patient contaminated with HBV must be called as the last patient?
(A) Yes
(B) No
(C) I do not know

Serological tests should be made after vaccination for the control of immunity?

(A) Yes

(B) No

(C) I do not know

Do you believe needle stick injury from hepatitis patient is highly contagious?
(A) Yes
(B) No
(C) I do not know

HBV patient should be treatment separately in clinic?
(A) Yes
(B) No
(C) I do not know

How strong in your personal worry about the risk of being infected by HBV
(A) Strong
(B) Moderate
(C) Low

(Attitude)

"I have moral responsibility to treat patients with HBV infection"

(A) Agree/strongly agree

(B) Neutral

(C) Disagree/strongly disagree

"I will treat patients with HBV infection"

(A) Agree/strongly agree

(B) Neutral

(C) Disagree/strongly disagree

"I can safely treat patients with HBV infection"

(A) Agree/strongly agree

(B) Neutral

(C) Disagree/strongly disagree

"I will let dentists treating patients with HBV treat my teeth"

(A) Agree/strongly agree

(B) Neutral

(C) Disagree/strongly disagree

Dentists have rights to know their patients' HBV infection statutes

(A) Agree/strongly agree

(B) Neutral

(C) Disagree/strongly disagree

"I am worry about being infected with HBV by my patients"

(A) Agree/strongly agree

(B) Neutral

(C) Disagree/strongly disagree

What is the reason behind not being vaccinated?
(A) Lack of motivation
(B) No need felt
(C) I'm vaccinated

What would be your reaction if you were found patient have HB?

(A) Don't have responsibility to treat

(B) Treat in hospital

(C) Treat in separately in clinic

(D) Treat as last patient

In case you are exposed to cough with blood infected with hepatitis B, how would you consider serological test?

(A) Not really important

(B) Ask to take vaccination

(C) Confirm with test initially 
(Practice)

The first action to be taken after needle stick injury is

(A) Washing with soap under running water.

(B) Calling for emergency services

(C) Getting the blood test done

How many doses of HBV vaccine did you receive?

(A) One dose

(B) Two doses

(C) Three doses

In case you are exposed to infected blood with hepatitis B, would you take vaccinations instead of confirming with serological test?

(A) Yes

(B) No

(C) I do not know

In case you are diagnosed with hepatitis $B$, do you avoid meeting with people?

(A) Yes

(B) No

(C) I do not know

HBV transmission from dentist to patient can be prevent with use of gloves?

(A) Yes

(B) No

(C) I do not know

Do you have to change gloves with all patients?

(A) Yes

(B) No

(C) I do not know

When exposure to blood stop on skin or eye do you take vaccine for protection?

(A) Yes

(B) No

(C) I do not know

In your daily clinical practice do you always use facemask?

(A) Yes

(B) No

(C) Sometime

In your daily clinical practice do you always use gloves?

(A) Yes

(B) No

(C) I do not know

Have you received the hepatitis B vaccine before?

(A) Yes

(B) $\mathrm{No}$

(C) I do not know

If yes, how many shots did you receive?
(A) 1
(B) 2
(C) 3 